\title{
Assistive Technology for Disabled Visual Artists: Exploring the Impact of Digital Technologies on Artistic Practice
}

\author{
Dr Chris Creed \\ School of Computing and Digital Technology \\ Birmingham City University \\ Millennium Point, \\ Birmingham, B4 7XG \\ chris.creed@bcu.ac.uk
}

[This is an Accepted Manuscript of an article published by Taylor \& Francis Group in Disability and Society on 11/05/2018, available online: http://www.tandfonline.com/10.1080/09687599.2018.1469400]

\begin{abstract}
Disabled artists with physical impairments can experience significant barriers in producing creative work. Digital technologies offer alternative opportunities to support artistic practice, but there has been a lack of research investigating the impact of assistive digital tools in this context. This paper explores the current practice of physically impaired visual artists and their experiences around the use of digital technologies. An online survey was conducted with professional disabled artists and followed up with face-to-face interviews with ten invited artists. The findings illustrate the issues disabled artists experience in their practice and highlight how they are commonly using mainstream digital technologies as part of their practice. However, there is little awareness around novel forms of technology (e.g. eye gaze tracking) that present new creative opportunities. The importance of digital tools for supporting wider practice (i.e. administrative and business tasks) was also highlighted as a key area where further work is required.
\end{abstract}

Keywords: assistive technology; disability art; digital tools; accessibility

[Manuscript Length: 6524 words]

\section{Introduction}

Professional disabled visual artists can experience significant barriers and difficulties in the production of their creative work. For instance, physically impaired artists can find 
it difficult to use common artistic tools such as brushes, pencils, and large canvases thus requiring them to adapt their practice to help facilitate the creative process. Traditional assistive tools such as mouth sticks, head wands, and custom designed grips (for holding brushes) can make creative work somewhat accessible, but research has shown they also present significant interaction issues and can lead to further health complications (Perera et al., 2007).

Digital technologies present alternative approaches for disabled artists as assistive tools, but no studies to date have explored in detail how professional artists (across a range of career stages and art forms) incorporate such technologies into their practice. These technologies include mainstream artistic software (e.g. Photoshop, Illustrator, etc.), mobile applications (e.g. Sketchbook Pro, Manga Studio, and ProCreate), alternative mouse and keyboard designs, trackballs, and switches. Moreover, there are many novel and innovative technologies such as eye gaze tracking (van der Kamp and Sundstedt, 2011; Heikkilä, 2013; Creed, 2016), mid-air gesturing and motion tracking (Creed, 2014; Diment and Hobbs, 2014), and voice recognition (Harada, et al., 2007) that have dropped in price significantly over the past couple of years. These technologies offer alternative assistive methods for disabled artists thus potentially helping to ensure they are not excluded or marginalised (Watling, 2011), yet it remains unclear whether artists are aware of these technologies and the extent to which they are utilising them as part of their practice.

Whilst views around digital technologies for disabled people have been explored in the context of perceptions, experiences, and wider issues (Harris, 2010; Borg et al., 2011; MacDonald and Clayton, 2013), their role has not been investigated in the context of professional disabled artistic practice. A deeper understanding of the current practice of physically impaired visual artists, the typical barriers they experience, and their 
existing usage of digital technologies can help to inform software developers and engineers in producing new tools that better support creative work.

To address the lack of work in this area this paper details research conducted to explore in more detail the current practice of professional physically impaired artists with a particular emphasis on the role of digital technologies. An online survey was conducted with professional visual artists to investigate and understand better the creative process and experiences of disabled artists $(n=18)$. Ten artists - ranging in career stage and artistic medium - were then invited for face-to-face interviews to discuss their practice in further detail. This research was undertaken in collaboration with a disability-led visual arts organisation (DASH - Disability Arts Shropshire) who support and commission disabled visual artists. DASH supported the project in terms of assisting with the recruitment of artists, as well as informing the design of the survey and interview questions to ensure key areas around artistic practice were addressed. Core themes emerging from this work are highlighted to explore how an artist's impairment can influence practice and the extent to which digital technologies are currently being utilised.

\section{Research Questions}

There were three key research questions that were investigated in this study:

1. How do physically impaired visual artists currently work? In particular, which art forms are they working in, what is their typical creative process, and which tools do they use to support their practice?

2. Which barriers do physically impaired artists currently experience around their work? What levels of personal assistance are required and how does this influence creative practice? 
3. Are physically impaired artists currently utilising digital technologies and assistive tools in their practice? If so, what are their experiences in using these tools? If not, are there any specific reasons why they are not utilising them to support creative work?

\section{Related Work}

Previous research studies have highlighted some of the issues disabled people experience around digital technologies (e.g. cost of devices, lack of support, negative attitudes to technology, technology abandonment, etc. - Phillips and Zhao, 1993; Riemer-Reiss and Wacker, 2000; Harris, 2010; Borg et al., 2011; MacDonald and Clayton, 2013). Many researchers have also questioned the impact of digital tools in supporting disabled people more widely (e.g. Goggin and Newell, 2003) - however, there has been little work to date exploring the current practice of professional disabled visual artists and their use of assistive and digital technologies. Boeltzig (2009) investigated the working methods and practice of "younger" artists (aged 18-25) across a range of different impairments (visual, physical, and cognitive) and highlighted the adaptations some artists had to make around their practice. However, this work was primarily with "non-professional" artists, so it is unclear whether the themes and approaches highlighted also apply to more established artists.

Perera et al. (2007) conducted a workshop with people who had a range of impairments to examine the methods they used to produce creative work as a hobby. They found that people used traditional assistive tools such as mouth sticks, head wands, and custom designed grips to help them work, but highlighted how slow, tedious, and tiring the production of creative work can be for people with physical impairments. Moreover, whilst these tools can help facilitate creative activities (to a 
certain extent), they can also lead to further physical issues such as chronic neck strain and damage to teeth. It is important to note that this work was also not conducted with professional disabled artists - as such, it is unclear whether professional artists are using the same types of assistive tools and whether they experience similar issues around their practice.

Other work has explored the potential of do-it-yourself (DIY) tools to support creative work. For instance, Coleman and Cramer (2015) highlight how different types of assistive devices (digital and non-digital adaptations of traditional tools) can be used to support disabled children who want to do creative work. Hurst et al. (2011) discuss the development of non-digital assistive tools to support people who cannot use their hands to produce creative outputs. Other studies have focused more on digital technologies for supporting disabled people - for instance, Diment and Hobbs (2014) developed the Kinect Virtual Art Program (KVAP) which used the Microsoft Kinect sensor to track the gestures of severely disabled children. These gestures were then used as input for producing creative work within a therapeutic context. Harada et al. (2007) explored the use of voice recognition as an input for creating graphical work and developed a system designed predominantly for people with motor impairments to allow them to create free-form drawings.

Studies have also looked at eye gaze tracking technology for creative work - the first study in this area was reported by Gips et al. (1996) who presented an application called "Eye Painting" that mimicked finger painting with a user's eyes to create basic coloured line drawings. Hornof and Cavender (2005) developed EyeDraw - an application for disabled children and young adults that allowed them to draw and manipulate basic shapes through gaze tracking. Similarly, Heikkilä (2013) developed a graphics application (EyeSketch) that allowed users to produce graphics and manipulate 
shapes via their eyes. van der Kamp and Sundstedt (2011) explored the combination of voice recognition (for menu selections) and eye gaze for drawing pictures in their application. Finally, Kwan and Betke (2011) developed eye-operated image editing software (Camera Canvas) for people with physical impairments.

These studies all provide examples for how digital technologies can potentially support people creating graphical and artistic work. However, none of the studies were focused around professional disabled artists - it is therefore unclear how professional artists currently work and how they are utilising digital technologies to support their practice.

\section{Methodology}

The research had two stages - the first was an online survey examining how professional physically impaired artists currently work, the types of barriers they experience, and the extent to which they use digital tools. To take part in the survey participants had to be practicing and professional artists (i.e. they have exhibited their work) with some form of physical impairment. Moreover, their primary art form needed to be in the visual arts - with a particular emphasis on painting, drawing, and digital art.

The survey consisted of sixteen questions - the initial questions focused on collecting basic demographic information about the artists (e.g. age, gender, etc.), identifying the nature of artists' physical impairments, and exploring their current creative process. In particular, questions focused on how often artists typically work, the medium(s) they work in (e.g. paint, pencil, oils, etc.), and how their impairments influence practice. Artists were also asked about the types of software they currently use to create their work (if applicable).

The next set of questions focused on whether artists used assistive tools in their practice and examined whether these tools were "traditional" (e.g. head wands and 
mouth sticks) or "digital" (e.g. eye tracking technology, speech input, custom keyboards, etc.). If artists stated that they did not use assistive technologies, they were asked to explain further if there were any particular reasons for not using them. Additional questions focused on how artists currently use the assistive tools they highlighted and any limitations they experience when using them. The survey concluded with a question around the extent to which artists required support from personal assistants.

The survey was completed by 25 artists although seven did not appear to have a physical impairment or did not provide sufficient detail in their responses to understand whether they met the full criteria for the study. These respondents were therefore not included in the final analysis. Artists reported working across a diverse range of disciplines such as painting, illustration, printmaking, clay and cardboard sculpting, eye gaze art, and digital photography (Table 1). The artists were aged between 20 - 74 and were at a variety of career stages including emerging, mid-career, and established. Artists also reported a wide range of different physical conditions including multiple sclerosis, motor neurone disease, generalized dystonia, muscular dystrophy, cerebral palsy, arthrogryposis, quadriplegia, and multiple joint arthritis.

The second stage involved investigating more deeply some of the subtleties and nuances around the creative practice of visual artists working across different media. Indepth interviews $(n=10)$ were therefore conducted with invited artists (from the survey) using a qualitative semi-structured interview method. A quota sampling approach was adopted to ensure that artists were invited across a range of career stages (emerging, mid-career, and established) and art forms - as well as those using different types of assistive technologies. 
The interviews focused on each artist's processes for creating their work, their views and experiences around the use of digital technologies in their practice, and their confidence around using technology to support their work (an issue that has been highlighted in the literature as negatively influencing technology adoption amongst disabled people - e.g. Harris (2010) and MacDonald and Clayton (2013)). Artists were also asked to bring along some of their work to help describe their creative process. Personal assistants who accompanied the artists were also encouraged to share their views or any relevant insights. All interviews were video recorded for later analysis.

Analysis of the survey and interview data utilised an ethnographic approach (Glaser and Strauss, 1967) where the responses were coded and analysed to identify initial themes and concepts. These concepts were then iteratively analysed and refined through repeatedly exploring the relationships between different themes. This aspect of the study was also conducted in collaboration with DASH and the key themes and interpretations were shaped and confirmed through their feedback and input.

\section{Findings}

\section{Impairment(s) Influencing Artistic Practice}

Artists described the variety of ways in which impairments influenced their working methods. One strong theme to emerge was around constraints in the types of art forms that were feasible for artists. For instance, artists commented that they worked in a particular way or used certain tools because they were more accessible to them than others (or were the only method available):

"Eyegaze art is the only way that I can express myself creatively ... I would like to study art again, particularly life drawing, but it's difficult to get to classes because of my condition" [Artist 4] 
"My impairments affect my creative methods profoundly. Basically the options I was left with at age 14 (and the decreasing number of them since) have curtailed most methods of expressing genuine creativity be it musical or visual" [Artist 16]

Several artists highlighted difficulties in their current practice around the traditional artistic tools and materials they use - for example, difficulties around squeezing paint out of tubes, finding palettes that are suitable for water colours, and how the use of screen beds and etching can be physical and tiring activities. Others have had to switch from traditional methods to digital tools as physical impairments have increasingly influenced their practice. In particular, artists commented on how they adapted their methods to work on smaller scales:

“... as a painter I have adjusted my methods to work on smaller scale, scanning images, using digital photography and Photoshop merged with traditional techniques. sometimes printing and painting back onto print...” [Artist 5]

"I use everyday materials, such as cardboard to create 3D sculptures. This medium allows me to make large scale work in smaller sections and sit down if needed." [Artist 15] 
Some of the artists highlighted how physical issues such as stiffness in hands, pain, motor impairments, and weakness influence their ability to create work:

"I work by sitting on a mat on the floor in a W seated position. this gives me a stable base which enables me to have an increased use of my arms. I am aware that sitting in this way is bad for my hips and causes increased muscle tone but there is no other way ... I need paint to be squeezed onto a flat pallet and water in a stable bowl to avoid spillage ... I work flat so I can lean on my wrist to limit involuntary movements" [Artist 9]

"Stiffness and issues with my hands/fingers which can affect my work ... My hands often feel very stiff which affect my psychomotor/drawing skills but I have developed a simple exercise for warming up (may be placebo, I don't care) and it eases the more drawing I do" [Artist 10]

Moreover, artists emphasized how they can typically only work for short periods - generally around 2-3 hours at a time. This point was closely related to a common theme around experiencing fatigue which 11 artists in the online survey explicitly highlighted as influencing their practice:

“Joint problems etc also limit very much my ability to paint landscapes/on location - all my work is studio based ... generally take photos in 2-3 hour sessions - longer not possible due to above issues and fatigue, partially caused by concentration needed for conversation" [Artist 14]

"I paint and draw standing up for short periods at a time ... I use digital drawing mostly using touch technologies for access and sometimes Wacom pen and pad on a low set desk sitting in my wheelchair for very short periods due to muscle fatigue" [Artist 8] 
Overall, the findings highlighted how the artists involved in the study have shaped and adapted their working methods and patterns to better support their individual creative practice. This, in turn, leads to highly individualised methods of working that typically require the use of specific tools and resources that enable artists to work independently (often with the support of personal assistants).

\section{The Role of Personal Assistants}

Another key theme to emerge was focused around personal assistance - 11 artists in the online survey commented on the need for help from others to enable them to work. The level of assistance required depended on the specific needs of each artist - for example, some were completely reliant on others:

"I need help with everything ... I cannot create any artwork without somebody to help me ... I have to have everything placed exactly right to enable me to draw / paint ... it helps if the person is patient and has an understanding of the nature and process of art making" [Artist 6]

Others required less support, but still needed help around setting up tools and for people to be available to assist during a creative session:

"I need a PA [personal assistant] to assist me to adjust height of canvasses and easels, to set up and assemble my space as I need it. To reach high and low equipment. Squeeze paint and mediums out for painting" [Artist 8]

"I do need help in the studio but so does Tracy Emen ... In the studio I employ help when I need it lifting and carrying moving canvasses" [Artist 18] 
“... setting up work/tools ... I need paint to be squeezed onto a flat pallet and water in a stable bowl to avoid spillage" [Artist 9]

Some artists did not need any help specifically around their creative work, but instead required support around transporting work and materials (either around a studio or to an exhibition). It is clear, therefore, that personal support from others plays a crucial role in supporting the creative practice of physically impaired visual artists with the specific needs highly dependent on individual requirements. As highlighted by numerous authors (e.g. Briesden, 1986; Davis, 1990; Morris, 1993; French, 1993), this type of personal assistance is essential in enabling disabled people to live and work independently. However, whilst it is clear that this support enables physically impaired artists to work, two artists also highlighted the "constraints" this places around their practice:

"I need someone to place the paper on a board and put a pen / pencil / brush in my hand ... the main limitation I have, is that I do not always have somebody to help me when I want to work" [Artist 6]

"I am a sculptor and a painter however I only sculpt if I have a support worker to lift and carry ...” [Artist 11]

It is often argued that digital technologies can address these issues and reduce reliance on others thus helping to support “independence”. However, self-sufficiency should not necessarily be the end goal with regards to using digital technologies in supporting artists - as French (1993) emphasises “... independence [for disabled people] can give rise to inefficiency, stress and isolation, as well as wasting precious time". It is also important to note that digital technologies and tools (designed and customised to 
the specific needs of a disabled artist) are unlikely to completely remove the need for personal support. For example, if an effective and efficient eye gaze tracking solution was developed to support the practice of disabled artists, it is likely that someone with more severe physical impairments would still need support in setting up the eye tracking sensor and running through the eye calibration process (i.e. an interactive softwaredriven process that allows the system to accurately track an individual's eyes).

Moreover, the use of digital technologies to support artistic practice can present issues around personal assistants needing significant technical experience to help troubleshoot or fix basic (or more complex) technical issues if the tools, sensors, or devices are not working. This, in turn, could make the creative process more problematic and frustrating for disabled artists if technical issues cannot be quickly resolved.

\section{Wide Usage of Mainstream Artistic Software}

14 artists from the online survey reported using mainstream digital technologies and software in their practice. In terms of software, Photoshop was by far the most commonly used (9 artists) - other software used included Illustrator, Indesign, After Effects, Final Cut Pro, GIMP, Flash, Lightroom, Paint, Artrage, and Revelation Natural Art. Four artists stated that they use mobile applications including Sketchbook Pro, Manga Studio, Ink, ProCreate, Pen and Ink, Graphite, Snapseed, Infinite Paint, and PicsPro.

Artists highlighted several advantages they found when using mainstream digital technologies and software - in particular, they commented how use of a Wacom tablet, for example, can help support dexterity as well as making it feasible to remove unintentional mistakes. Artists also commented on how a digital approach offered more flexibility and freedom in their practice. 
"Although my style is very similar to traditional pen \& ink work I now almost always work digitally after developing rough sketches. This is simply because it makes allowances for sudden stiffness or twitches (which also happen...) which can easily be altered in a digital format ... I have truly embraced the dork side and enjoy all forms of technological development which can be used to enhance visual communication" [Artist 10]

"I prefer to draw digitally rather than paint ... always looking to technology to improve my techniques and practice. Particularly interested in touch and freedom of movement where I don't have to hold equipment and something that can enable me to make a big gesture with very little movement, considering my limited scale of movement" [Artist 8]

However, some artists also highlighted the issues they experience when using mainstream digital tools - these included issues around lacking control when using a stylus with artistic applications, difficulty around operating multi-touch tablets (typically due to motor impairments), the use of trackballs as a mouse replacement leading to repetitive strain injuries, the different feel of using a digital approach over traditional tools (which provide tangible feedback and can incorporate more "randomness" into work), and issues around the use of digital equipment that may be too big or heavy to use:

"The digital responses are less intuitive and lack the gestural impact that one material interacting with another has. less accidental marks and no translucent colour layering" [Artist 5]

"I have tried drawing apps and a stylus but lack the control ... when using ipad to draw I 
cant stable my wrist" [Artist 9]

"I scan my drawings (with assistance) and work on them in photoshop. I am able to use photoshop on my own, using a mouse, but I find the keyboard very difficult to use" [Artist 6]

These issues highlight the important role of the input devices that disabled artists use to control and manipulate mainstream artistic software. The variety of tools used often provide methods of interaction that are significantly different from a traditional mouse and keyboard. This can lead to issues as the emphasis in designing mainstream creative applications (e.g. Photoshop) leans heavily towards a more traditional mouse and keyboard interaction. This mode of interaction therefore encourages interface design elements such as small icons which take up minimal screen space and are easy to select with a mouse (for non-disabled users), as well as keyboard shortcuts that help to speed up common activities and actions (e.g. copy and paste).

However, to take one example, the use of a technology such as eye gaze tracking presents a completely different form of interaction in comparison to a mouse and keyboard (Jacob, 2003). Multiple research studies have highlighted how users (disabled and non-disabled) find it difficult to select small targets via eye gaze due to a range of technical and physiological constraints (Bates and Istance, 2002; Ashmore et al., 2005; Findlater et al., 2010). Therefore, attempting to use this form of interaction (or others) in conjunction with interfaces that have been designed primarily for non-disabled users operating a mouse and keyboard - is likely to be problematic.

This particular example was supported by Artist 4 - this artist utilises eye gaze tracking technology to support her creative practice. Whilst this technology assists her in accessing and using creative software, she also highlighted how this approach “... 
takes a long time which is frustrating, because I compare how quickly I would work if I could still use my hands". This was emphasised in a demo she provided of how she uses eye gaze tracking with Natural Revelation Art package - an application she uses because it has larger icons and buttons than those commonly used in other creative packages (likely due to the fact that children are a key target audience for this software). Whilst the use of eye gaze tracking to control this application was somewhat accessible in enabling her to produce creative work, it was also clear that simple actions such as selecting a "pen" tool often had to be repeated on multiple occasions (thus potentially leading to frustrating user experiences).

To draw on work by Akrich (1993), these findings highlight how the "scripts" used by designers of mainstream creative software still do not appear to prioritise or emphasise inclusive design. Moreover - consideration has not been given to the plethora of ways in which disabled people may want to use and access the software and as such they may have to endure a sub-standard interaction experience (or be completely excluded). Simply bolting on digital technologies (such as eye gaze tracking, speech recognition, or motion tracking) onto existing interfaces is unlikely to provide an optimal experience and means that disabled artists will likely have to find workarounds to try and make software accessible. If designers can create "scripts" or "scenarios" that are more inclusive in nature - combined with iterative design and development undertaken in close collaboration with disabled people and other stakeholders (in real world longitudinal scenarios) - the potential for creating more effective and efficient methods may be increased.

\section{Specialised Assistive Technology Not Widely Used}

10 artists from the online survey reported not currently using any digital assistive tools (e.g. eye gaze tracking, speech recognition software, etc.) to support their working 
practice. In particular, none of the artists reported using traditional assistive tools such as head wands, mouth sticks, or custom-designed grips for creative work. Those who are using assistive technology are making use of trackballs, eye tracking technology, elbow crutches, and wheelchair accessories (e.g. for holding cameras). In terms of software, artists reported using speech-to-text applications (e.g. Dragon NaturallySpeaking) and accessibility features such as screen magnifiers and virtual keyboards.

Whilst these tools can provide benefits to artists, they also present other issues for instance, one artist using a wheelchair camera holder experiences significant issues in attaching it to her chair and then attaching the camera to the arm (Artist 3). The arm is also not long enough and thus the artist has to bend forward to see through the viewfinder (which can lead to lower back issues). In terms of trackballs, Artist 7 commented that they enable finer control of the mouse (when coupled with software that slows down the cursor), but that after repeated use it has resulted in a repetitive strain injury.

Other artists have experienced issues with accessibility software - for example, Artist 18 commented on difficulties experienced with speech-to-text software in that it did not always "... catch many of the little words..." the artist used. There also appeared to be a lack of awareness around the variety of digital technologies that could be used for assistive purposes (as suggested by the lack of discussion in artist responses). Several artists openly expressed this view:

"I am sure there are many other digital what-sits which might help me i.e. voice activation but I have not got to grips with this technology ... the main limitation I have, is that I don't know enough about what is possible / available" [Artist 6]

"I dare say there's stuff that could help. I just don't know where to start" [Artist 16] 
"I am not aware of any tools, but would be open to exploring them" [Artist 15]

"My take on 'digital art' is to draw picture in Word, using the 'insert' option, for shapes and colours" [Artist 12]

The reasons for this lack of awareness are unclear, although could be related to the novelty of some of the technologies. For instance, eye gaze tracking is not a commonly used technology and may not be familiar to artists who have not explicitly researched or explored this method of interaction. Moreover, as highlighted in previous work (Harris 2010; McDonald and Clayton, 2013), cost could also be significant issue with the perception that innovative technologies are likely to be extortionately expensive (which is not necessarily always the case).

\section{Importance of Wider Practice}

Artist 18 highlighted an essential point that has received no attention from researchers to date which is related to issues around administrative tasks. The artist's personal assistant summarised this effectively (the artist has cerebral palsy):

“... a simple task, such as ... a seven-line email can take 40 to 60 minutes to complete... extrapolate this for the number of emails she receives - her gallery, art institutions, suppliers, media, students - plus ordering of supplies, arranging print-making, planning work for a show and catalogue, and the time and effort involved are considerable and exhausting. It is unusual ... to be able to get into the studio before midday most days." [Artist 18]

Whilst this point was not explicitly raised by other artists, it will likely apply more widely for artists who may have issues in using traditional input tools for 
computers (i.e. a mouse and keyboard). It is therefore not sufficient for digital tools to only make the artistic and creative process more accessible - they also need to support all of the wider tasks involved in an artist's practice. This is a neglected research area where further work is required.

\section{Conclusion}

This study focused on three core research questions to explore the creative practice of professional physically impaired visual artists and their use of digital technologies. These questions placed a particular emphasis on the way in which artists currently work (e.g. which types of art forms, typical creative process, etc.), the barriers and issues they currently experience around their practice, and the extent to which they are currently utilising digital technologies and assistive tools to support their practice.

The findings highlighted that artists are working professionally across a variety of different art forms including painting, illustration, printmaking, sculpting, eye gaze art, and digital photography. In terms of artistic process, methods of working are clearly dependent upon the individual artist and their unique requirements - although several key themes emerged. For instance, some artists worked with particular art forms as these were the only ones that were feasible or accessible to them. Several artists have had to adapt their practice over time as their impairments have developed with artists highlighting, for example, how they have switched to working on smaller scales and then scaling up their work. Artists also discussed ways in which they attempt to reduce the impact of physical impairments influencing their process through ergonomically adapting the way in which they work (sometimes in ways that will likely lead to further physical issues - as in the case of Artist 9 working on floor in a $\mathrm{W}$ seated position).

In terms of issues that artists experience around their practice, fatigue was highlighted as a common barrier to working thus resulting in many of the artists only 
being able to work for short periods at a time. Other issues focused around being able to move and transport tools, adjusting the height of easels, squeezing paint out of tubes, and a range of other challenges (dependant on the specific experience of individual artists). As such, personal assistance was emphasised by many artists as being a crucial element of their practice in enabling them to work and to have control over their creative workflow. However, whilst assistants are essential in supporting the work of disabled artists, a couple of artists also expressed some frustration that they could only work when assistants were available. It is often argued that digital technologies could help to provide disabled people with more self-sufficiency and independence although this was only a desire that Artist 9 explicitly commented on ("I believe that I could be completely independent with the right equipment/software"). Similar to previous work, this suggests that self-sufficiency and complete independence is not necessarily a specific goal for the majority of artists involved in this project.

The findings around the artists' use of digital technologies and assistive tools in their practice were surprising. In particular, it was found that mainstream digital technologies and software are widely used and that these tools are supporting disabled artists to produce creative work professionally. This was a surprising finding as these tools would often be considered inaccessible to disabled people due to the design of the interfaces being developed for people using a traditional mouse and keyboard. Moreover - this finding contradicts previous work in the field (e.g. Harris, 2010) which has highlighted how disabled people are not commonly using mainstream technologies and software. This change in trend may likely be due - in some part - to the wider choice of potential applications available (e.g. on mobile platforms) and improvements made to the accessibility of a range of devices (e.g. accessibility features available on Windows, the Mac operating system, iOS, and Android). Whilst these accessibility 
features can make mainstream software somewhat accessible, it can also lead to interaction issues as artists are having to "bolt" different input methods onto applications that were not necessarily designed to support those methods of interaction (e.g. using eye gaze tracking with Photoshop).

In contrast, only a small minority of the artists reported using more novel technologies such as eye gaze tracking and speech recognition to support their practice. As noted in other research (Harris 2010; McDonald and Clayton, 2013) this seems to be due to a lack of awareness and access to these products - with cost often being a significant barrier. However, whilst the prices of these technologies have dropped significantly (i.e. typically around $£ 100$ ), there still seems to be limited awareness of these tools and their potential to support practice. There also remains relatively few tools available that are designed to specifically support disabled people for creative work. As highlighted, this results in artists having to adapt themselves to use mainstream technologies as opposed to tailoring these tools to support their specific needs and requirements. Therefore, whilst professional creative work is clearly possible using novel digital technologies (as exemplified by Artist 4 using eye gaze tracking), it can be a time-consuming, tedious, and frustrating process that requires significant effort and persistence to produce work.

The research conducted in this study highlights both how digital technologies can potentially support creative practice for disabled artists and also introduce further issues and complications. To address some of these issues, future work in this area needs designers, developers, and user experience specialists - in collaboration with disabled artists and other stakeholders - to create digital tools that better support people wanting to produce creative work (using a variety of input methods). Whilst alternative approaches for producing creative work are made available through the increased 
accessibility of innovative technologies, the risk is that these technologies are simply "bolted" onto mainstream tools, applications, and software. This will likely result in usability issues as these mainstream applications have not been designed for novel methods of interaction such as eye gaze tracking, mid-air gesturing, speech recognition, or switch-based interaction. It is crucial, therefore, that a collaborative approach is adopted to increase the likelihood that future tools are designed to address the specific needs and requirements of disabled artists. Moreover, it is essential that future research not only focuses on creative work, but also all the activities associated with the wider practice of disabled artists (e.g. the business side of their practice). This is an area that has received no attention from researchers to date, but is essential to ensure that artists can manage all aspects of their practice.

In summary, this research provides a deeper insight into the working practice of professional physically impaired visual artists and demonstrates the variety of ways in which artists are producing their work (including barriers, use of digital technologies, etc.). Novel technologies present alternative approaches for disabled and non-disabled artists to produce creative work, although it was clear from this study that disabled artists are not aware of these possibilities. Furthermore, it is not yet clear whether technologies such as eye gaze tracking and speech recognition can genuinely enhance the practice of disabled artists more widely or whether they simply introduce more complexities and challenges. This therefore represents an interesting area for future research to help better determine the long-term impact of these digital and assistive technologies to support the creative practice of disabled artists. 


\begin{tabular}{|c|c|c|c|c|}
\hline Artist & Gender & Age & Physical Impairment(s) & $\operatorname{Art} \operatorname{Form}(s)$ \\
\hline A1 & $\mathrm{F}$ & 58 & $\begin{array}{l}\text { Severe pain in hands, } \\
\text { shoulders, base of spine and } \\
\text { hips }\end{array}$ & Fused glass art \\
\hline A2 & $\mathrm{F}$ & 26 & $\begin{array}{l}\text { Generalised dystonia - causing } \\
\text { abnormal posture and } \\
\text { spasms/pain. Affects mouth, } \\
\text { neck, right hand and right } \\
\text { foot. }\end{array}$ & Photography \\
\hline A3 & $\mathrm{F}$ & 55 & $\begin{array}{l}\text { Multiple sclerosis - decreased } \\
\text { grip in hands and fatigue. }\end{array}$ & Photography \\
\hline A4 & $\mathrm{F}$ & 49 & $\begin{array}{l}\text { Motor neurone disease - } \\
\text { unable to use hands. }\end{array}$ & $\begin{array}{l}\text { Digital art via eye gaze } \\
\text { tracking }\end{array}$ \\
\hline$\overline{A 5}$ & $\mathrm{M}$ & 49 & $\begin{array}{l}\text { Mobility, chronic pain, and } \\
\text { fatigue. }\end{array}$ & $\begin{array}{l}\text { Painting with mixed media } \\
\text { and collage }\end{array}$ \\
\hline A6 & $\mathrm{F}$ & 61 & $\begin{array}{l}\text { Muscular dystrophy - all } \\
\text { muscles are very weak - } \\
\text { experiences pain and fatigue. }\end{array}$ & Drawing / painting \\
\hline A7 & $\mathrm{F}$ & 42 & $\begin{array}{l}\text { Mobility impaired with } \\
\text { limited dexterity. }\end{array}$ & Visual art and sound \\
\hline $\mathbf{A 8}$ & $\mathrm{F}$ & 49 & $\begin{array}{l}\text { Mobility impaired in all limbs } \\
\text { and joints creating restricted } \\
\text { movement. No muscle mass } \\
\text { creates physical and mental } \\
\text { fatigue over short periods of } \\
\text { movement. }\end{array}$ & $\begin{array}{l}\text { Painting, drawing, and digital } \\
\text { art via mobile applications }\end{array}$ \\
\hline A9 & $\mathrm{F}$ & 20 & $\begin{array}{l}\text { Severe Cerebral Palsy } \\
\text { Quadriplegia. Mixture of } \\
\text { spastic, athetoid and } \\
\text { ataxic/involuntary } \\
\text { movements. }\end{array}$ & $\begin{array}{l}\text { Pencil, acrylic, paint, clay and } \\
\text { glazes }\end{array}$ \\
\hline A10 & $\mathrm{M}$ & 49 & $\begin{array}{l}\text { Multiple sclerosis - resulting } \\
\text { in limited mobility and } \\
\text { fatigue. Neuropathic pain }\end{array}$ & Digital illustrator \\
\hline
\end{tabular}




\begin{tabular}{|c|c|c|c|c|}
\hline & & & $\begin{array}{l}\text { affecting arms and legs. } \\
\text { Stiffness and issues with } \\
\text { hands/fingers. }\end{array}$ & \\
\hline A11 & $\mathrm{F}$ & 39 & Hip amputee & Sculptor / painter \\
\hline A12 & $\mathrm{F}$ & 74 & $\begin{array}{l}\text { Parkinson's, arthritis, and } \\
\text { knee replacement. }\end{array}$ & Wax \\
\hline A13 & M & 60 & $\begin{array}{l}\text { Two fingers and a thumb on } \\
\text { each hand. Some degree of } \\
\text { arthritis and pain, along with } \\
\text { mobility problems due to } \\
\text { arthritis in ankle and knee } \\
\text { joints. }\end{array}$ & Drawing and collage \\
\hline A14 & $\mathrm{F}$ & 41 & $\begin{array}{l}\text { Ulcerative colitis with } \\
\text { associated enteropathic } \\
\text { arthropathy affected mainly } \\
\text { hands and feet, bilateral } \\
\text { frozen shoulders (mainly } \\
\text { released) and bilateral carpal } \\
\text { tunnel syndrome }\end{array}$ & $\begin{array}{l}\text { Drawing / painting (graphite } \\
\text { for initial drawings, oil paint } \\
\text { for paintings) }\end{array}$ \\
\hline $\mathbf{A 1 5}$ & $\bar{M}$ & 41 & Right leg above knee amputee & Cardboard sculptor \\
\hline A16 & $\mathrm{F}$ & 63 & Mobility, pain, and fatigue. & Digital designer \\
\hline A17 & $\mathrm{F}$ & 22 & Pain and fatigue & $\begin{array}{l}\text { Wood, paper, plastics, and } \\
\text { ceramics (mixed media) }\end{array}$ \\
\hline A18 & $\mathrm{F}$ & 60 & Cerebral palsy & Painter \\
\hline
\end{tabular}

Table 1: An overview of the artists who completed the survey (including selfidentification of physical impairments) - artists in bold are those invited for interviews.

\section{References}

Akrich, M. 1992. “The De-Scription of Technical Objects” In Shaping

Technology\Building Society, edited by W. Bijker \& J. Law. 
Ashmore, M., A.T. Duchowski, and G. Shoemaker. 2005. "Efficient eye pointing with a fisheye lens.” Paper presented at Proceedings of Graphics interface, 203-210.

Bates, R. and H. Istance. 2002. “Zooming Interfaces!: Enhancing the Performance of Eye Controlled Pointing Devices.” Paper presented at fifth international ACM conference on Assistive technologies, 119-126.

Boeltzig, H., J. Sullivan Sulewski, and R. Hasnain. 2009. “Career development among young disabled artists." Disability \& Society 24 (6): 753-769.

Brisenden, S. 1986. "Independent living and the medical model of disability." Disability, Handicap \& Society 1 (2): 173-178.

Borg, J., S. Larsson, and P. Östergren. 2011. “The right to assistive technology: For whom, for what, and by whom?" Disability \& Society 26 (2): 151-167.

Coleman, M. B., and E. S. Cramer. 2015. "Creating Meaningful Art Experiences With Assistive Technology for Students With Physical, Visual, Severe, and Multiple Disabilities.” Art Education 68: 6-13.

Creed, C., R. Beale, and P. Dower. 2014. “Digital Tools For Physically Impaired Visual Artists" Poster presented at the 16th International ACM SIGACCESS Conference on Computers \& Accessibility, New York, 253-254. 
Creed, C. 2016. "Eye Gaze Interaction for Supporting Creative Work with Disabled Artists." Poster presented at the British Human-Computer Interaction Conference. Bournemouth.

Davis, K. 1990. “A Social Barriers Model of Disability: Theory into Practice (the emergence of the 'Seven Needs')." Derbyshire Coalition of Disabled People (http://www. leeds. ac. uk/disability-archiveuk/index. html).

Diment, L., and D. Hobbs. 2014. “A Gesture-Based Virtual Art Program for Children with Severe Motor Impairments-Development and Pilot Study.” Journal of Assistive, Rehabilitative \& Therapeutic Technologies, 2 (1).

Findlater, L., A. Jansen, K. Shinohara, M. Dixon, P. Kamb, J. Rakita, and J.O. Wobbrock. 2010. "Enhanced area cursors: reducing fine pointing demands for people with motor impairments." Paper presented at 23nd annual ACM symposium on User interface software and technology, 153-162.

French, S. 1993. "What's So Great About Independence." In Disabling barriersenabling environments, 44-48.

Gips, J., and P. Olivieri. 1996. EagleEyes: An Eye Control System for Persons with Disabilities. Paper presented at the Eleventh International Conference on Technology and Persons with Disabilities, 1-15.

Glaser, B, and A. Strauss. 1967. The Discovery of Grounded Theory. London: Weidenfield \& Nicolson. 
Goggin, G. and C. Newell. 2003. Digital disability: The social construction of disability in new media. Rowman \& Littlefield.

Harada, S., J. Wobbrock, and J. A. Landay. 2007. "Voicedraw: A Hands-Free VoiceDriven Drawing Application for People with Motor Impairments." Paper presented at the 9th International ACM SIGACCESS Conference on Computers and Accessibility, Arizona, 27-34.

Harris, J. 2010. "The use, role and application of advanced technology in the lives of disabled people in the UK." Disability \& Society 25 (4): 427-439.

Heikkilä, H. 2013. "EyeSketch: A Drawing Application for Gaze Control.” Paper presented at Conference on Eye Tracking South Africa (ETSA). South Africa, 71-74.

Hornof, A. J., and A, Cavender. 2005. "EyeDraw: Enabling Children with Severe Motor Impairments to Draw With Their Eyes.” Paper presented at the SIGCHI Conference on Human Factors in Computing Systems, Oregon, 161-170.

Hurst, A., and J. Tobias. 2011. "Empowering Individuals with Do-It-Yourself Assistive Technology." Paper presented at 13th international ACM SIGACCESS Conference on Computers and Accessibility, Dundee, 11-18.

Jacob, R .J. and K .S. Karn. 2003. "Eye tracking in human-computer interaction and usability research: Ready to deliver the promises." In The Mind's Eye, 573-605. 
van der Kamp, J., and V. Sundstedt. 2011. "Gaze and Voice Controlled Drawing.” Paper presented at the 1st Conference on Novel Gaze-Controlled Applications, Karlskrona.

Kwan, C. and M. Betke. 2011. "Camera Canvas: Image Editing Software for People with Disabilities." In Universal Access in Human-Computer Interaction. Applications and Services, edited by C. Stephanidis, 146-154. Berlin: Springer.

Macdonald, S. J., and J. Clayton. 2013. "Back to the Future, Disability and the Digital Divide." Disability \& Society 28 (5): 702-718.

Morris, J. 1993. Independent lives? Community Care and Disabled People. London: Macmillan.

Perera, D. P., J. R. T. Eales, and K. Blashki. 2007. "The Drive to Create: An Investigation of Tools to Support Disabled Artists." Paper presented at the 6th ACM SIGCHI conference on Creativity \& Cognition, Washington, 147-152.

Phillips, B. and H. Zhao. 1993. "Predictors of assistive technology abandonment." Assistive technology 5 (1): 36-45.

Riemer-Reiss, M.L. and R. R. Wacker. 2000. Factors associated with assistive technology discontinuance among individuals with disabilities. Journal of Rehabilitation 66 (3): 44-50. 
Watling, S. (2011) “Digital exclusion: coming out from behind closed doors.” Disability \& Society 26 (4): 491-495. 